\title{
Digital Revolution In Veterinary Anatomy: Confection of Anatomical Models of Canine Stomach by Scanning and Three-Dimensional Printing (3D)
}

\author{
Revolución Digital en Anatomía Veterinaria: Confección de Modelos Anatómicos \\ del Estómago Canino Mediante Escaneo e Impresión Tridimensional (3D)
}

Conrado Henrique Hackmann; Daniela de Alcântara Leite dos Reis \& Antônio Chaves de Assis Neto

HACKMANN, C. H.; DOS REIS, L. D. A. \& DE ASSIS NETO, A. C. Digital revolution in veterinary anatomy: confection of anatomical models of canine stomach by scanning and three-dimensional printing (3D). Int. J. Morphol., 37(2):486-490, 2019.

SUMMARY: Three-dimensional (3D) scanning and printing can contribute to the area of Veterinary Anatomy, producing anatomical models that can be used in teaching. The objective of this project was to apply the $3 \mathrm{D}$ digitalization and printing to produce models of the canine stomach, and make these models available as an alternative tool of study in the practical classes of veterinary anatomy. The stomachs of dogs were digitized and printed in 3D models. Anatomical aspects were easily identifies in the models as compared with stomach original. The results of this project clearly demonstrated that the digitalization and 3D printing from the dog stomach come to strongly contribute to the teaching of veterinary anatomy, currently playing an important role by producing replicas which present desirable anatomical characteristics from organ.

KEY WORDS: Gross Anatomy; 3D Printing; Veterinary Education; Anatomical Models; Veterinary Anatomy.

\section{INTRODUCTION}

Anatomy learning is part of the training process for several health professionals. In veterinary medicine, this knowledge is essential in the training of clinicians, pathologists, surgeons, and many other specializations in this career. The methods used for the teaching of anatomy can be categorized in dissection, interactive multimedia, procedural anatomy, surface and clinical anatomy, and imaging (Sugand et al., 2010).

The difficulty in obtaining and maintaining cadavers for anatomy teaching has been considered an ineffective teaching tool due to inaccessibility (Parker, 2002; Salazar, 2002; Nicholson et al., 2006; Kinnison et al., 2009; Sugand et al.; Preece et al., 2013). The high cost required for the maintenance of cadavers, and of laboratories suitable to maintain those items, are obstacles faced by the institutions that use this tool, a fact that caused many laboratories to abandon these practices. In addition, the main chemical used to preserve cadavers is formaldehyde, a substance harmful to the health of students, teachers and workers involved in the daily operation of a classic anatomy laboratory (Raja \& Sultana, 2012; McMenamin et al., 2014).
Many institutions rely primarily on the use of books with 2D images and written information, as well as classes, through which information of clinical cases and animations is passed verbally and through photographs when teaching anatomy, given the impossibility of using corpses for such studies (Sugand et al.; Preece et al.). However, articles published by Preece et al. and Khalil et al. (2005) have shown that such methods are less efficient for learning when compared to others, such as the use of anatomical models. A large list of alternative methods has already been described in countries such as the United States, Australia and the United Kingdom, like plastination, three-dimensional imaging (3D) and body painting, which presented positive impacts in the scientific community (McMenamin et al.; AbouHashem et al., 2015).

Among the new methods highlighted, digitalization followed by three-dimensional (3D) printing for the production of anatomical models has been gaining strength globally, since they are becoming increasingly fast, economical and easy-to-use techniques (McMenamin et al.). The use of three-dimensional anatomical model has been 
used efficiently how a good teaching tools and applied for surgical planning (Nicholson et al.; Rengier et al., 2010).

A recent research in our Lab has showed success with three-dimensional scanning and printing of dogs and horses skeletal parts used as teaching tools in veterinary anatomy classes (Reis et al., 2017). This project aims to apply such technology to the production of anatomical models of organs, assessing whether the produced parts bear the same anatomical structures visual characteristics as the organs used in the study of veterinary anatomy.

\section{MATERIAL AND METHOD}

A dog from Anatomy Lab from School of Veterinary Medicine and Animal Science of the University of Sao Paulo (FMVZ-USP) was dissected. The specimen was previously fixed in $10 \%$ formaldehyde solution and stored in $30 \%$ saline solution.

A macroscopic 3D scanning system (model "Go!Scan 3D" Creaform ${ }^{\circledR}$ ) was used to scan the preserved organs. This handheld 3D scanner features a data acquisition method known as triangulation and a self-positioning system. The data is obtained through two cameras and a laser beam. A data acquisition and interface software known as "VXElements" was responsible for managing the image capture. This software features an automatic accurate texture mapping with adjustable contrast and brightness, provides real-time 3D image visualization and is capable of performing surface reconstruction. To facilitate the scanning process, "targets" were used: small adhesive buttons whose center has a metallic sphere and helps the portable 3D scanner to identify surfaces.

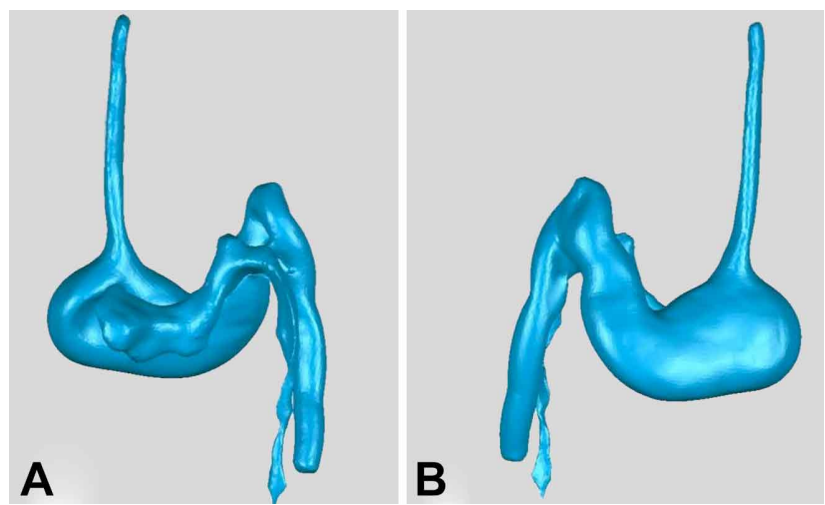

Fig. 1. Surface visceral position of the dog's stomach seen in the ventral (A) and dorsal (B) positions evidencing its connection with the esophagus in the cardia region and the ascending duodenum. In the image we can observe the relation of the pancreas to the stomach and the descending duodenum.
After their 3D scanning, the images were submitted to a final editing process. For this, "Geomagic $® "$ software, which brings tools to make image printing possible, was used. After editing, the final images were saved with STL extension (Standard Triangle Language), accepted by the three-dimensional printer.

The "Stratasys Mojo 3D Printer®" was used in this project. This piece of equipment uses thermoplastic filaments to produce the final piece, together with resin supporting materials which are later removed in a washing process, giving rise to the final part.

\section{RESULTS AND DISCUSSION}

The edited final images produced during the organs scanning process are shown as Figures 1 to 3. Those are images used to print the pieces and also make up a bank of digital images that can be used in anatomy classes.
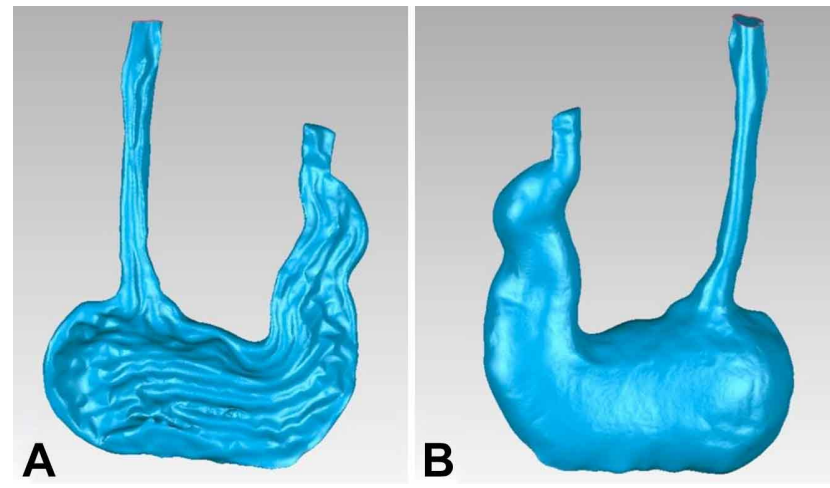

Fig. 2. Anatomical features in a $3 \mathrm{D}$ digital model of stomach of the dog. Facies Visceralis: (A) Internal view and (B) External surface.

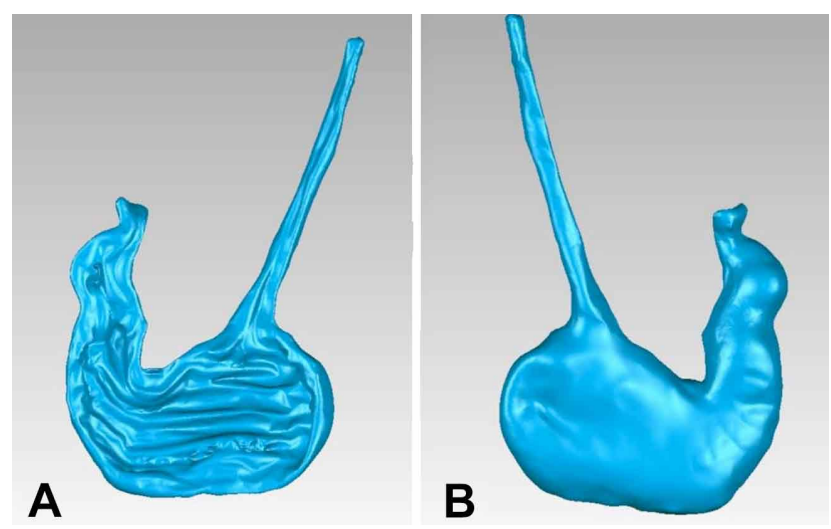

Fig. 3. Anatomical features in a $3 \mathrm{D}$ digital model of stomach of the dog. Facies Parietalis: (A) Internal view and (B) External surface. 
Figures 4 to 8 show the final results of the printed organs. Initially, the printed pieces were accompanied by the resin mold that enveloped them, which helps in the support of the final part during the printing process and in the construction of the final model.

In this project, anatomical models of the stomach of dogs were produced, exhibiting characteristics which are visually faithful to the organs scanned by a 3D MRI scan, functioning as true-to-life replicas of those organs. Figure 9 shows the similarity between the organ (A) preserved in 30 $\%$ saline solution, a scanned image (B) in STL format, and the $3 \mathrm{D}$ printing process final result $(\mathrm{C})$.

The printed models showed details of anatomical structures similar to the actual stomach. The teaching of Anatomy has always been the subject of great discussions due to the use of corpses and, consequently, to the use of

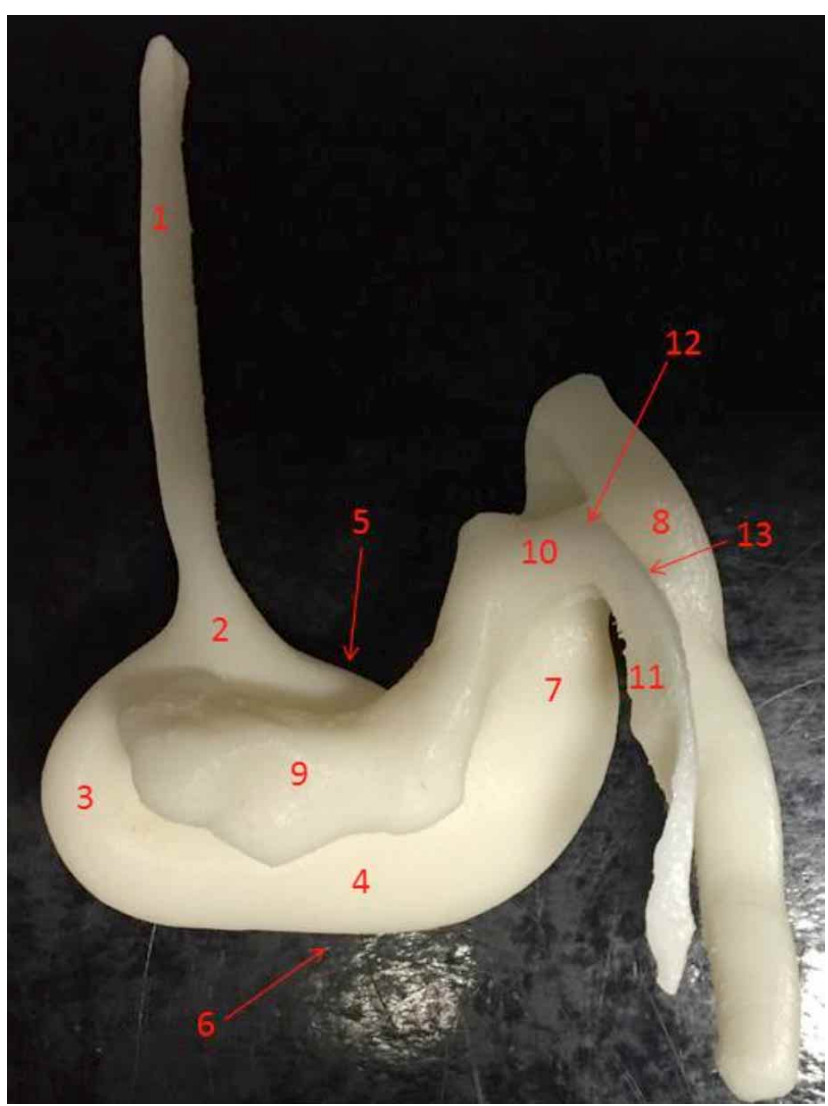

Fig. 4. Anatomical model printed in 3D showing the anatomical relationship among the esophagus, the visceral view of the stomach, the pancreas and the descending duodenum, in a ventral position, considering a dog in anatomical position. 1- Esophagus; 2- Stomach cardia; 3- Fundus of the stomach; 4. Body of the stomach; 5- Lesser curvature of the stomach; 6- Greater curvature of the stomach; 7 Pylorus of the stomach; 8- Descending duodenum; 9- Right lobe of the pancreas; 10- Body of the pancreas; 11- Left lobe of the pancreas; 12- Pancreatic duct; 13- Accessory pancreatic duct.

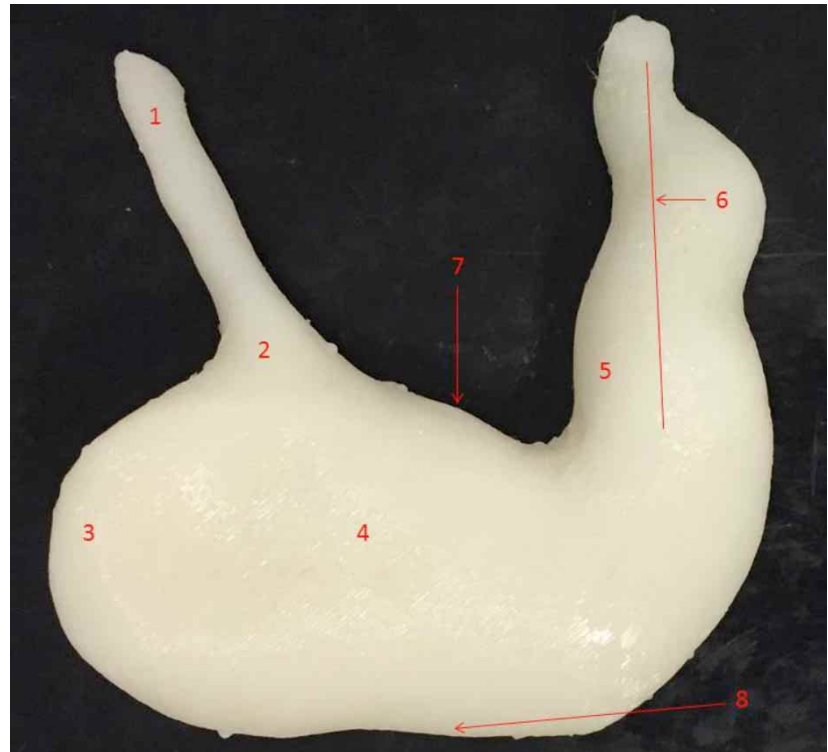

Fig. 5. Anatomical model printed in 3D showing the diaphragmatic view of the stomach of a dog in anatomical position. 1- Esophagus; 2- Stomach cardia; 3- Fundus of the stomach; 4. Body of the stomach; 5 - Pylorus of the stomach; 6- Pyloric antrum; 7- Lesser curvature of the stomach; 8- Greater curvature of the stomach.

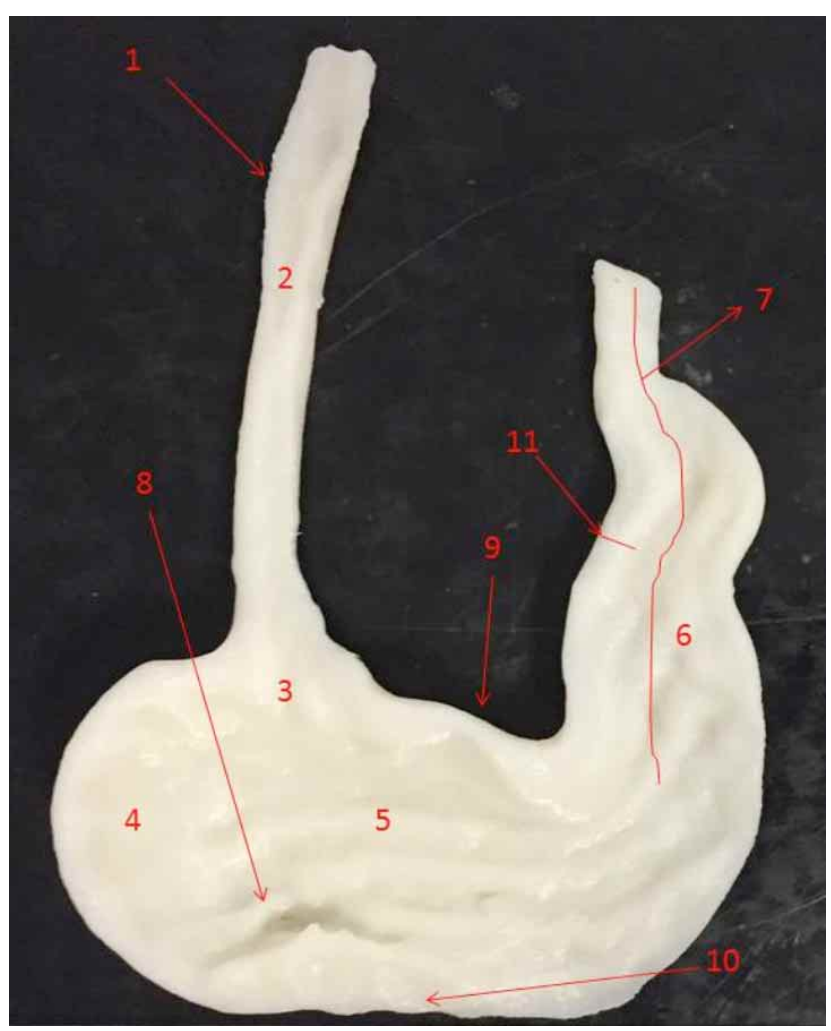

Fig. 6. 3D anatomical model showing the interior of the dog's stomach in anatomical position. 1- Esophagus; 2- Esophageal glands; 3Aglandular region ; 4- Region of the gastric glands fundus; 5- Region of the pyloric glands in the body of the stomach; 6- Piloro; 7- Pyloric antrum; 8- Gastric folds; 9- Lesser curvature of the stomach; 10Greater curvature of the stomach; 11- Pyloric muscular wall. 
products like formaldehyde for the conservation of the parts. The use of copies of visceral organs will alleviate these inconveniences (McMenemin et al., 2014; Chen et al., 2017).

In the anatomical models, it is possible to identify the different regions of the canine stomach (aglandular and glandular), the regional anatomy of the organ (cardia, body and the pyloric antrum), as well as important anatomical features of the species, like the greater and lesser curvatures of the stomach. In addition, the topographic relationships of the stomach with other organs like the esophagus, the descending duodenum and the pancreas can be observed. Due to the fact that the printed models are produced from a thermoplastic material, its use as a teaching material would not be restricted to anatomy laboratories, but could also be used in other places such as libraries and classrooms (Wen,

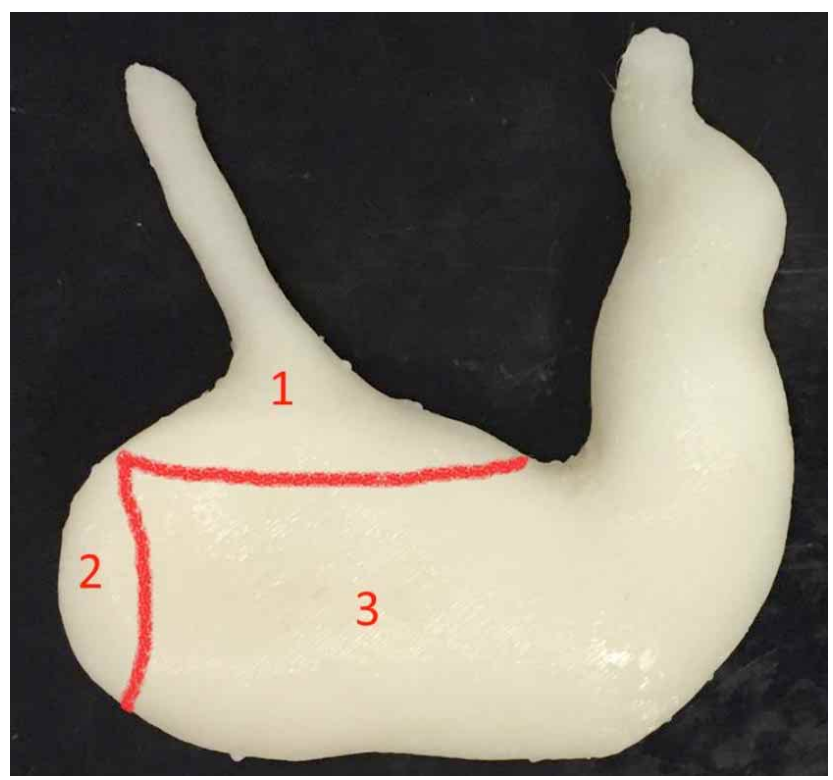

Fig. 7. 3D anatomical model showing the projection of the gastric mucosa of the stomach of a dog, visceral face. 1, aglandular part; 2 , region of the glandular glands; 3 , region of the gastric glands fundus; 4 , region of the pyloric glands.
2016). This is an advantage of our research because it will allow students to study the anatomy of the stomach in other places and even at home - not only in Anatomy Laboratories - because the biomodels are light, resistant and produced with a material similar to plastic. Another byproduct of our work was the creation of digitized files saved in PDF and STL formats, with the possibility of printing copies at any time. 3D technology in veterinary medicine is still little used, and the use of these models plays an important role in the introduction of biomodels as an alternative didactic tool in the teaching of anatomy.

Stomach models were also produced as three-dimensional images. Using this format, students can interact rotating the image at various angles and identifying the particularities and anatomical structures of the organ. As shown in the figures, if applied in the classroom, the anatomical models of the stomach did not present disadvantages in relation to the real animal model. Classes may be comparatively more complete, since other models of stomachs of other species may also benefit from the use of 3D technology.

\section{CONCLUSION}

The study of anatomy is of paramount importance for the training of good veterinarians and health professionals. Due to ethical, moral, environmental and financial issues, the study of anatomy through cadavers is under discussion and, therefore, it is fundamental to develop alternative methods for the study of this science, allowing its continuity given its due role in the formation of professionals. The results of this project clearly demonstrated that the digitalization and $3 \mathrm{D}$ printing from the dog stomach come to strongly contribute to the teaching of veterinary anatomy, currently playing an important role by producing
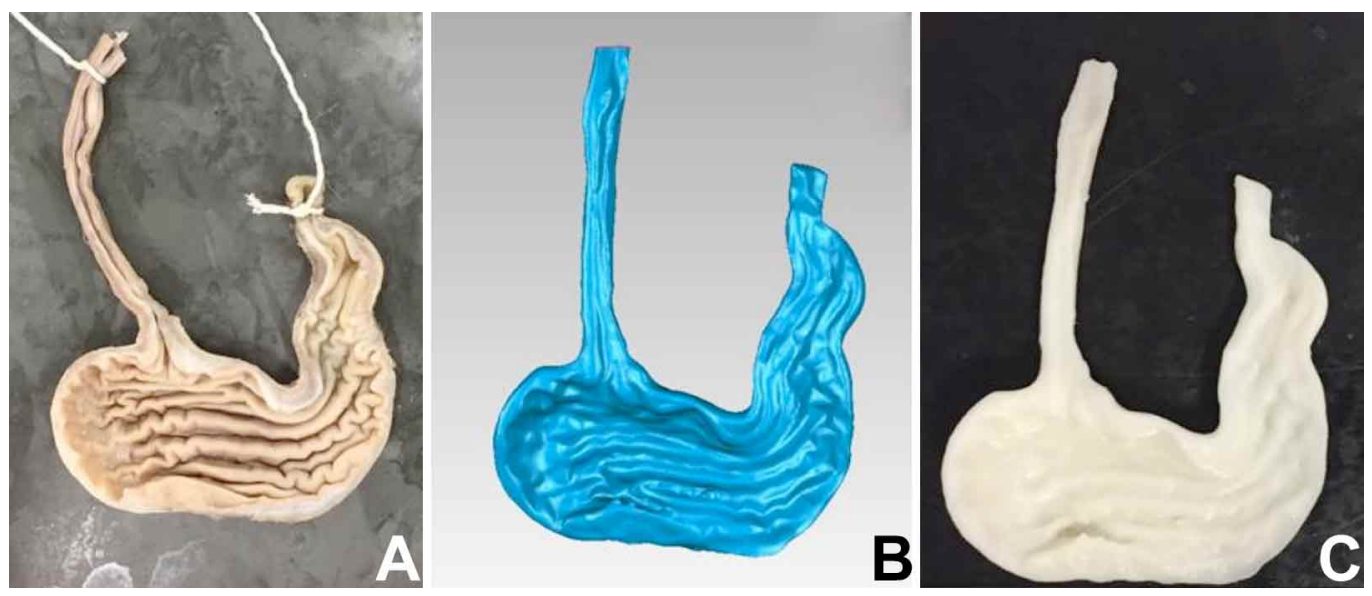

Fig. 8. Inner face of the dog's stomach in anatomical position of a specimen preserved in $30 \%$ saline solution; STL image produced by the "Geomagic" software (B) and $3 \mathrm{D}$ printed model. 
replicas which present desirable anatomical characteristics from organ.

\section{ACKNOWLEDGMENTS}

We appreciate the constant support that has given us to "Programa Unificados de Bolsas" and RENOVALAB grant from University of São Paulo (USP), São Paulo, Brazil. Franceliusa Delys de Oliveira and Paulo Ramos Silva Santos for help with 3D scanner machine.

HACKMANN, C. H.; DOS REIS, L. D. A. \& DE ASSIS NETO, A. C. Revolución digital en anatomía veterinaria: confección de modelos anatómicos del estómago canino mediante escaneo e impresión tridimensional (3D). Int. J. Morphol., 37(2):486-490, 2019.

RESUMEN: El escaneo e impresión tridimensional (3D) puede contribuir al área de Anatomía Veterinaria, produciendo modelos anatómicos que pueden usarse en la enseñanza. El objetivo de este proyecto fue aplicar la digitalización e impresión 3D para producir modelos del estómago canino y hacer que estos modelos estén disponibles como una herramienta alternativa de estudio en las clases prácticas de anatomía veterinaria. Los estómagos del perro fueron digitalizados e impresos en modelos 3D. Los aspectos anatómicos se identificaron fácilmente en los modelos en comparación con el estómago original. Los resultados de este proyecto demostraron claramente que la digitalización y la impresión en 3D del estómago del perro contribuyen en gran medida a la enseñanza de la anatomía veterinaria y que actualmente desempeña un papel importante, al producir réplicas que presentan características anatómicas deseables a partir de órganos.

PALABRAS CLAVE: Anatomía; Impresión 3D; Educación veterinaria; Modelos anatómicos; Anatomía veterinaria.

\section{REFERENCES}

Chen, S.; Pan, Z.; Wu, Y.; Gu, Z.; Li, M.; Liang, Z.; Zhu, H.; Yao, Y.; Shui, W.; Shen, Z.; Zhao, J. \& Pan, H. The role of three-dimensional printed models of skull in anatomy education: a randomized controlled trail. Sci. Rep., 7(1):575, 2017.

AbouHashem, Y.; Dayal, M.; Savanah, S. \& Strkalj, G. The application of 3D printing in anatomy education. Med. Educ. Online, 20:29847, 2015.

Khalil, M. K.; Johnson, T. E. \& Lamar, C. H. Comparison of computerbased and paper-based imagery strategies in learning anatomy. Clin. Anat., 18(6):457-64, 2005.

Kinnison, T.; Forrest, N. D.; Frean, S. P. \& Baillie, S. Teaching bovine abdominal anatomy: use of a haptic simulator. Anat. Sci. Educ., 2(6):280-5, 2009

McMenamin, P.; Quayle, M. R.; McHenry, C. R. \& Adams, J. W. The production of anatomical teaching resources using three-dimensional (3D) printing technology. Anat. Sci. Educ., 7(6):479-86, 2014.
Nicholson, D. T.; Chalk, C.; Funnell, W. R. \& Daniel, S. J. Can virtual reality improve anatomy education? A randomised controlled study of a computer-generated three-dimensional anatomical ear model. Med. Educ., 40(11):1081-7, 2006.

Parker, L. M. What's wrong with the dead body? Use of the human cadaver in medical education. Med. J. Aust., 176(2):74-6, 2002.

Preece, D.; Williams, S. B.; Lam, R. \& Weller, R. "Let's get physical": advantages of a physical model over 3D computer models and textbooks in learning imaging anatomy. Anat. Sci. Educ., 6(4):216-24, 2013.

Raja, D. S. \& Sultana, B. Potential health hazards for students exposed to formaldehyde in the gross anatomy laboratory. J. Environ. Health, 74(6):36-40, 2012.

Reis, D. A. L.; Gouveia, B. L. R.; de Alcântara, B. M.; Saragiotto, B. P.; Baumel, E. E. D.; Ferreira, J. S.; Rosa Júnior, J. C.; de Oliveira, F. D.; Santos, P. R. S. \& de Assis Neto, A. C. Biomodelos ósseos produzidos por intermédio da impressão 3D: uma alternativa metodológica no ensino da anatomia veterinária. Rev. Grad. U. S. P., 2(3):47-53, 2017.

Rengier, F.; Mehndiratta, A.; von Tengg-Kobligk, H.; Zechmann, C. M.; Unterhinninghofen, R.; Kauczor, H. U. \& Giesel, F. L. 3D printing based on imaging data: review of medical applications. Int. J. Comput. Assist. Radiol. Surg., 5(4):335-41, 2010.

Salazar, I. Coming changes in veterinary anatomy: What is or should be expected? J. Vet. Med. Educ., 29(3):126-30, 2002

Sugand, K.; Abrahams, P. \& Khurana, A. The anatomy of anatomy: a review for its modernization. Anat. Sci. Educ., 3(2):83-93, 2010.

Wen, C. L. Homem Virtual (Ser HUMANO VIRTUAL 3D): a integração da computação gráfica, impressão $3 \mathrm{D}$ e realidade virtual para aprendizado de anatomia, fisiologia e fisiopatologia. Rev. Grad. U. S. P., 1(1):7-16, 2016.

Corresponding author:

Antonio Assis neto

Department of Surgery

School of Veterinary Medicine and Animal Science

University of São Paulo

Prof. Dr. Orlando Marques de Paiva Avenue, 87

ZC 05508270 - Cidade Universitária

São Paulo/SP

BRAZIL

Email: neto.antonioassis64@.gmail.com

Received: 28-11-2018

Accepted: 28-01-2019 